\title{
APRENDIZAGEM BASEADA EM PROBLEMAS: UM ESTUDO DE CASO NA DISCIPLINA DE TRATAMENTO DE ÁGUA, EFLUENTE E LODOS
}

\author{
APRENDIZAJE BASADO EN PROBLEMAS: UN ESTUDIO DE CASO EN LA \\ DISCIPLINA DE TRATAMIENTO DE AGUA, EFLUENTE Y LODOS
}

\section{PROBLEM-BASED LEARNING: CASE STUDY IN THE DISCIPLINE WATER TREATMENT, EFFLUENT AND SEWAGE}

\author{
Regina de C. O. MACHADO ${ }^{1}$ \\ Giani M. B. BOHM ${ }^{2}$ \\ Emerson de MORAES ${ }^{3}$
}

RESUMO: Toda Instituição de Ensino que oferte cursos profissionais carrega consigo um grande comprometimento, pois são responsáveis pela formação de um profissional plenamente apto e consciente de suas competências e habilidades, que devem ser usados em sua atuação no mercado de trabalho competitivo e seletivo. A partir disso e apoiado na literatura existente, a Aprendizagem Baseada em Problemas (ABP) pode ser um caminho, como sendo uma ferramenta facilitadora para que os discentes possam assimilar mais facililmente as competências (atitudes, conhecimento e habilidades), as quais podem ser aplicadas em sua futura carreira profissional de forma contundente. Portanto, a presente pesquisa teve por objetivo avaliar a ABP aplicada a disciplina de Tratamento de Água, Efluentes e Esgotos do curso Técnico em Química do IFG, realizada no ano de 2013. Para tanto, esta pesquisa baseou-se no procedimento técnico atrelando estudo de caso. A coleta de dados foi proveniente da observação participante, de questionários e do protótipo gerado. De forma geral, os resultados evidenciaram que a ABP promoveu uma maior integração e envolvimento dos alunos, motivada pela comunicação e participação bilateral docente/discente bem como o uso de tecnologias dispostas como ferramentas para crescimento pessoal, intelectual e profissional, pois os alunos ao utilizarem problemas práticos e reais ganharam destreza na resolução de problemas de ordem prática e profissional.

PALAVRAS-CHAVE: Ensino-aprendizagem. Metodologia alternativa. Modelo tradicional. Material didático.

RESUMEN: Cualquier institución educativa que ofrezca cursos profesionales lleva consigo una gran responsabilidad traducida en la formación de un profesional plenamente apto de sus competencias y habilidades en la eminente actuación en nuestro competitivo y selectivo mercado de trabajo. A partir de esta premisa, apoyándose en la

${ }^{1}$ Instituto Federal de Goiás ( IFG), Luziânia - GO - Brazil. Professora do departamento de Química. E-mail: regcarvoliveira@gmail.com

${ }^{2}$ Instituto Federal Sul-Riograndense (IFSUL), Pelotas - RS - Brazil. Professora Titular do departamento de Engenharia e Gestão Ambiental. E-mail: bohmgiani@gmail.com

${ }^{3}$ Instituto Federal Sul-Riograndense (IFSUL), Pelotas - RS - Brazil. Mestrando no programa de Engenharias e Ciências Ambientais. E-mail: ebohm2@gmail.com 
literatura vasta existente, se ve el norte apuntado al Aprendizaje Basado en Problemas $(P B L)$, como una herramienta facilitadora para que los alumnos puedan fácilmente asimilar las competencias (actitudes y conocimiento), los cuales, pueden ser aplicados en su futura carrera profesional de forma contundente. Por lo tanto, esta investigación tiene como objetivo evaluar el PBL aplicado a la disciplina de Agua, Efluentes y Tratamiento de Alcantarillado del Curso Técnico en Química del IFG, que se realizó en el año 2013. Para ello, esta investigación se basó en el procedimiento técnico vinculado al procedimiento estudio de caso. Los datos fueron recolectados a través de la observación participante, cuestionarios y el prototipo generado. En general, los resultados mostraron que el PBL fue útil para incluir mayor integración e implicación de los alumnos, motivados por la comunicación y participación bilaterales de profesores y alumnos, así como el uso de tecnologías como herramientas para crecimiento personal, intelectual y profesional, pues los alumnos al utilizar problemas prácticos y reales ganaron destreza en la resolución de problemas de orden práctico y profesional.

PALABRAS CLAVE: Enseñanza-aprendizaje. Metodología alternativa. Modelo tradicional. Material didáctico.

ABSTRACT: Any Educational Institution that offers professional courses carries with it a great responsibility, that should lead to the formation of a fully qualified professional who has proper competences and abilities that are required to a competitive and selective labor market. Therefore, based on this premise and on the existing literature, we believe that Problem-based Learning (PBL) could be a guide, once it is a facilitating tool for students to assimilate skills more easily (attitudes and knowledge), which can be applied in their future professional career in a forceful way. Therefore, the present research lies with the objective of evaluating the PBL applied to the discipline of Water, Effluents and Sewage Treatment of the Technical Course in Chemistry of the IFG, that was held in the year 2013. In order to do it, this research was based on the technical procedure and a case study. Data were collected through participant observation, questionnaires and the generated prototype. In general, the results have showed that the PBL was helpful to include greater integration and involvement of the students, motivated by bilateral teacher/student communication and participation, as well as the use of technologies as tools for personal, intellectual and professional growth, as students using and real problems led them to learn skills in solving problems of both practical and professional nature.

KEYWORDS: Teaching-learning. Alternative methodology. Traditional model. Didactic material.

\section{Introdução}

Dentre os abissais desafios imputados aos docentes quanto ao que tange o ensino técnico profissionalizante, é imperativo fazer destaque para a absorção de conhecimento de forma ampla do discente buscando atrelar à extração máxima de suas potencialidades para que, ao se romperem as barreiras físicas da sala de aula, esse dicente possa incorporar 
seu conhecimento absorvido na iminente inserção ao mercado de trabalho e às suas necessidades. Nesse contexto, é necessário que os discentes deixem de apenas teorizar e na prática, despertar ações dos alunos para o novo, para instigar suas curiosidades e desejo de descobrir algo, tornando-os também responsáveis por sua aprendizagem.

Todavia, a realidade da grande maioria das Instituições traz consigo a metodologia de outrora do formato ensino-aprendizagem convencional, em que o ensino fica restrito à sala de aula e torna coadjuvante a aprendizagem prática, trantando-a com um mero reforço para absorção acadêmica do aluno. Ocasionalmente há uma interação teórico/prática, porém com a grade currilicular enrigecida em cadeiras, a fusão multidiciplinar orbita no utópico.

Nesse sentido, o ensino baseado na Metodologia da Problematização (Problem Based Learning pode ser uma boa estratégia para que os alunos desenvolvam suas habilidades e obtenham uma formação mais ampla. Essa aprendizagem é uma abordagem de ensino que tem sido utilizada com sucesso por mais de 30 anos e continua a ganhar aceitação em várias áreas e disciplinas. De fato, o ensino de determinados temas de uma disciplina - os problemas - são extraídos por meio da observação da realidade vivenciada pelos alunos. (Tomas, 2000)

Uma ferramenta que ajuda na discussão de um problema detectado na realidade é o Arco de Maguerez (Figura 1), que é executado por meio de progressão pedagógica (BERBEL, 2012, p. 103-120) através de cinco etapas: observação da realidade (problema), discussão dos pontos-chave, teorização, formulação de hipóteses de solução e aplicação à realidade.

Figura 1 - O arco de Maguerez

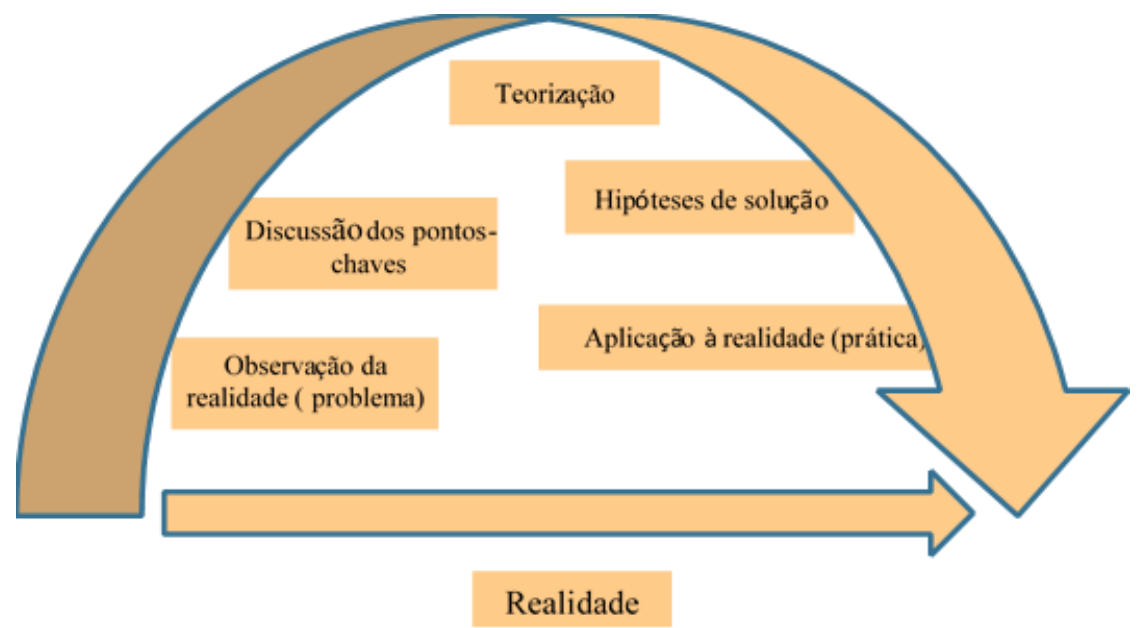

Fonte: Berbel (2016) 
Uma parte importante desse ciclo é a identificação das deficiências de conhecimento do grupo que dificultam ou impedem a proposição de soluções para o problema (pontos-chave). Segundo Lopes, 2011, p. 1275-1280, as deficiências encontradas pelo grupo e com foco na solução do problema central, já identificado, gera uma etapa de estudos autodirigidos. Esses processos são planejados de forma que os alunos sejam orientados na busca de novos conhecimentos científicos necessários para resolver o problema atribuído (HOLLENBECK, 2008). Além disso, essas abordagens são centradas nos alunos que são capacitados para realizar pesquisas, integrar teoria e prática, assim como aplicar conhecimentos e habilidades para solucionar um problema previamente definido (SAVERY, 2006). Portanto, os métodos de problematização pela observação da realizade encorajam o aprendizado individual através da construção coletiva de um conhecimento mais profundo, tornando os estudantes responsáveis pela própria aprendizagem (QUEEN'S UNIVERSITY, 2003).

Estudos realizados por Larmer, 2010, apontam que para o desenvolvimento dessa metodologia são necessários oito elementos: conteúdos que tenham significado, a necessidade de conhecer, uma questão norteadora, voz e escolha do estudante, competências do século XXI, aprofundamento da questão, crítica e revisão exposição do trabalho ao público.

A partir desses pressupostos, este trabalho de pesquisa desenvolveu uma abordagem baseada na ABP, aplicada a uma disciplina (Tratamento de Água, Efluentes e Resíduos) do Curso Técnico em Química do Instituto Federal de Goiás - Câmpus Luziânia, com o objetivo de descrever e discutir a experiência parcial dessa metodologia, assim como dos resultados, mostrando seus limites intrísecos e contextuais e indicando os ganhos com relação ao desenvolvimento tanto discente quando docente.

\section{Design metodológico}

A proposta da Metodologia da Problematização (MP) foi desenvolvida durante as aulas da disciplina de Tratamento de Águas, Efluentes e Resíduos do $4^{\circ}$ ano do curso Técnico Integrado em Química do Instituto Federal de Goiás - Câmpus Luziânia, localizado na cidade de Luziânia, durante o ano de 2013.

A sequência didática da MP foi estruturada de modo a contemplar objetivos conceituais, procedimentais e os atitudinais. Para alcançar esses objetivos, as estratégias e os recursos das aulas foram divididos em momentos de aprendizagem interligados, 
assim, possibilitando que a docente se adaptasse de acordo com as particularidades de seus alunos e às condições da escola.

No primeiro momento, a professora se deteve ao levantamento de concepções prévias dos estudantes sobre a temática com uma questão norteadora: "Qual a percepção da comunidade sobre o tratamento de água, efluentes e resíduos?”. Após a problematização inicial, acerca da realidade vivenciada pelos alunos, foi proposto o desenvolvimento de entrevistas com a comunidade sobre a temática a ser estudada. As questões abordadas durante as entrevistas foram propostas pelos próprios discentes, com a orientação da professora. Foram entrevistados sete membros da comunidade pertencente ao IFG - Câmpus Luziânia (identificados por P01-P07). Foi adotado o modelo de entrevistas semiestruturadas e as falas foram submetidas aos procedimentos da Análise Textual Discursiva conforme método descrito por Moraes e Galiazzi (2007), constituída por três etapas: a unitarização, na qual ocorreu a fragmentação dos textos em unidades de significado; a categorização, momento em que os fragmentos foram agrupados de acordo com suas semelhanças semânticas; e a etapa de comunicação, onde foram elaborados os textos descritivos e interpretativos desse processo de categorização. As categorias emergentes foram apresentadas e discutidas a partir dos fragmentos mais significativos extraídos das falas dos entrevistados. Em alguns casos, para melhor descrever e analisar o entendimento dos entrevistados foram construídas subcategorias dentro da respectiva categoria de análise. Esse momento teve a duração de cinco aulas. A partir dessas concepções foi possível estruturar os passos seguintes relativos ao encaminhamento do plano de ensino da disciplina: as questões didáticas e teóricas.

Assim, para retomar as questões discutidas anteriormente, especialmente no que se refere à importância da água, e introduzir novos elementos às discussões, a professora explorou com seus alunos os conteúdos apresentados no vídeo "Desconstruindo Paris" $\begin{array}{llllll}\text { apresentado pelo discovery no } & \text { s dite }\end{array}$ $<$ https://www.youtube.com/watch?v=rOzw3bBLT4o>.

Posteriormente, após dar os primeiros passos para a compreensão da teoria científica e para o desenvolvimento da concepção, os estudantes e a professora fizeram visitas técnicas a lixões, estações de tratamento da água, efluentes e resíduos, nas cidades de Luziânia, Brasília e Goiânia (figura 02 A e 2B).

Figura 2 - Visita técnica 


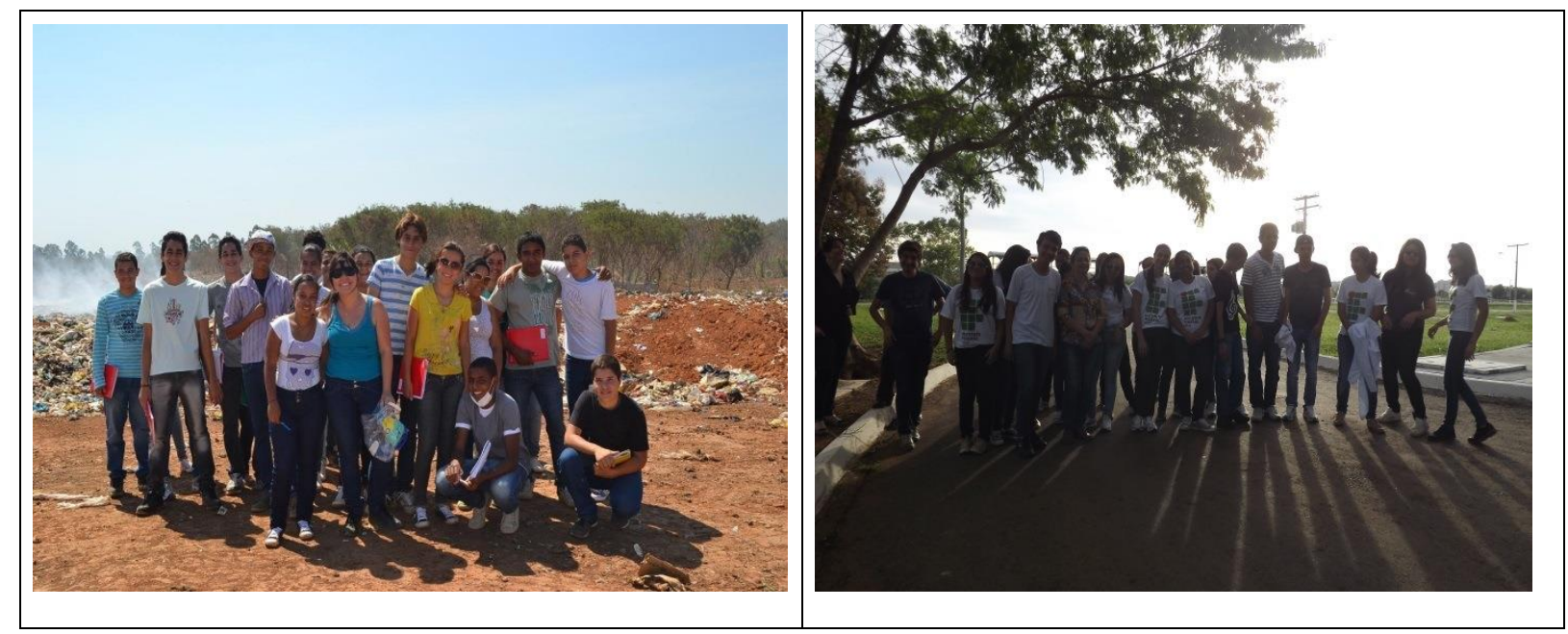

Fonte: IFG (2017)

A fim de explorar os conceitos, após a visita, os estudantes deviam identificar as etapas envolvidas no tratamento de água, efluentes e esgoto, assim como soluções para a utilização de resíduos gerados nas estações. Essa atividade foi desenvolvida com os alunos divididos em grupos de 4, utilizando a pesquisa como modalidade didática. Posteriormente, os alunos realizaram a exposição dos estudos em grupos em sala de aula, por meio de seminários, em quais discorreram sobre seus achados de pesquisa. Durante esse processo, a professora atuou como mediadora durante e ao final das apresentações conduzia os estudantes na identificação das proximidades e distanciamentos das pesquisas. Para subsidiar a instrumentalização teórica dos estudantes, foram trabalhados diversos textos referentes ao tema como por exemplo: Baran, 2005; Campos e Jardim, 2003; Grassi, 2001; Guimarães e Nour, 2001; Fadine e Fadine, 2001; Jardim, 2001; 2003; Mozeto, 2001; Rosa e Rocha, 2003; Silva e Andrade, 2003.

$\mathrm{Na}$ continuidade das atividades, foram realizadas as aulas práticas. Essa modalidade didática consistiu na construção de um protótipo de uma estação de tratamento de água. Para tanto, o sistema de tratamento de água convencional foi dividido nas seguintes unidades: mistura rápida, floculação, decantação, filtração, desinfecção, conforme apresentado na Figura 3. O protótipo construído foi baseado no modelo do protótipo de Lira et al, 2012 e Kondo, 2007, porém trazendo inovação quanto ao material utilizado que foi totalmente originado de reaproveitamento e reutilização de materiais descartados no lixo.

Após a construção do protótipo, os alunos fizeram apresentações orais sobre o tema abordado e sobre o próprio protótipo construído para a comunidade acadêmica do 
IFG - campus Luziânia. É importante destacar que, durante a aplicação dessa metodologia foram realizadas avaliações formativa e somativa.

Assim, após as apresentações dos projetos pelos alunos, a fim de avaliar a metodologia adotada e habilidades desenvolvidas pelos discentes, sob seus pontos de vista, bem como para dar um feedback sobre o projeto e a atuação de todos durante o processo discutiu-se o desempenho do grupo de forma a fazer uma avaliação em conjunto. A metodologia foi questionário fechado, onde os alunos realizaram a avaliação do processo de ensino com questões relacionadas à metodologia, ao conteúdo e à participação individual e em grupo. Essa avaliação foi aplicada em sala de aula a um grupo de 30 alunos em encontro presencial, sem a necessidade dos estudantes se identificarem. Para a elaboração desse questionário foi utilizada a escala de pontuação tipo Likert, com pontuações variando de 1 a 5 para cada item abordado, quanto maior o valor atribuído, mais positivo é o resultado. Para fins de classificação as médias foram consideradas baixas de 1 a 3; satisfatórias de 3,1 a 3,8; alta de 3,9 a 4,4 e excelente de 4,5 a 5.

\section{Resultados e discussões}

A partir da avaliação feita em sala de aula foi possível perceber que os alunos ao trabalharem sob a ABP, em um primeiro momento de discussão, encontraram várias lacunas e dúvidas sobre o problema proposto. No entanto, foi observado que a metodologia de ensino adotada aproximou os alunos e despertaram o interesse em adquirir conhecimentos sobre o tópico em questão, devido à contextualização que foi realizada entre o conteúdo a ser ensinado e a realidade imediata vivenciada pelos alunos.

Ademais, nos relatos dos entrevistados sobre as questões de tratamento de esgoto e água, veio à tona a concepção da importância do saneamento básico, o qual é percebido como sinônimo de saúde, o que foi enfatizado na fala dos entrevistados: [... ] o tratamento de esgoto é muito importante (P01, P02, P03, P04, P05, P06 e P07).[...]. O relato dos entrevistados, apesar de entener os problemas locai, ao citar tratamento de esgoto, os entrevistados delimitaram as políticas publicas nacionais de saneamento básico.

Em outras falas também emergiram conceitos sobre "o que é tratamento de esgoto":

[...] tratamento de esgoto é uma obrigação do estado (P01, P03)

[...] tratamento de esgoto é um tratamento de resíduos (P02, P04, P05, P06, P07) 
Tais representações trouxeram implicações pedagógicas na abordagem científica dos problemas de saneamento e a importância do papel da escola na busca de formas de superação das políticas locais envolvidas no saneamento básico, cujo caminho precisa envolver os processos de saneamento.

Além disso, o cenário criado (ou situação-problema) propiciou aos alunos o levantamento de questões e a procura de soluções através da promoção de atividades de investigação, referidas na literatura da especialidade por inquiry. Essa metodologia pode ser definida como uma abordagem orientada para a investigação, por partir de questões (levantadas pelos alunos após apresentação do cenário) e envolver a procura de soluções (BARROWS, 1996; BORDENAVE; PEREIRA, 1980).

Quanto à exploração do vídeo como forma de discussão e aprendizagem, esse projeto possibilitou a compreensão de aspectos históricos, científicos e culturais. Inovações arquitetônicas e urbanísticas da cidade de Paris foram mostradas, além do caráter histórico e social do tratamento da água (problemas de saúde vivenciados na época devido a uma epidemia ocorrida na cidade). O vídeo também trouxe elementos iniciais para a compreensão de aspectos teóricos relacionados ao conteúdo da disciplina. De fato, a exibição do vídeo facilitou o entendimento de conceitos teóricos dos discentes, o que minimizou a distância da realidade cotidiana desses, desse modo, as aulas foram mais dinâmicas, uma vez que aproximou a teoria à prática de uma forma mais criativa. A exibição do vídeo em sala de aula também foi utilizada nos trabalhos realizados por Ribeiro et al (2015), os quais demonstraram melhorias significativas na compreensão de conteúdos abordados.

Afora isso, a construção dos conceitos referentes ao tratamento de água e esgoto através do protótipo mobilizou os alunos para o objeto de estudo, além de ter possibilitado o envolvimento dos estudantes com as investigações científicas (Figura 3). As aulas práticas proporcionaram aos alunos o desenvolvimento da capacidade de pensar, de absorver conceitos básicos, conteúdos e procedimentais e atitudinais, necessários para a resolução de problemas práticos (KONDO; ROSA, 2007). Além disso, o protótipo contribuiu para o desenvolvimento cognitivo, pois facilitou a construção de relações e significados, favorecendo a aprendizagem construtiva. A utilização de protótipos em sala de aula também foi realizada com sucesso por Lira et al (2012).

Figura 3 - Vista geral do protótipo com todas as etapas do tratamento convencional 


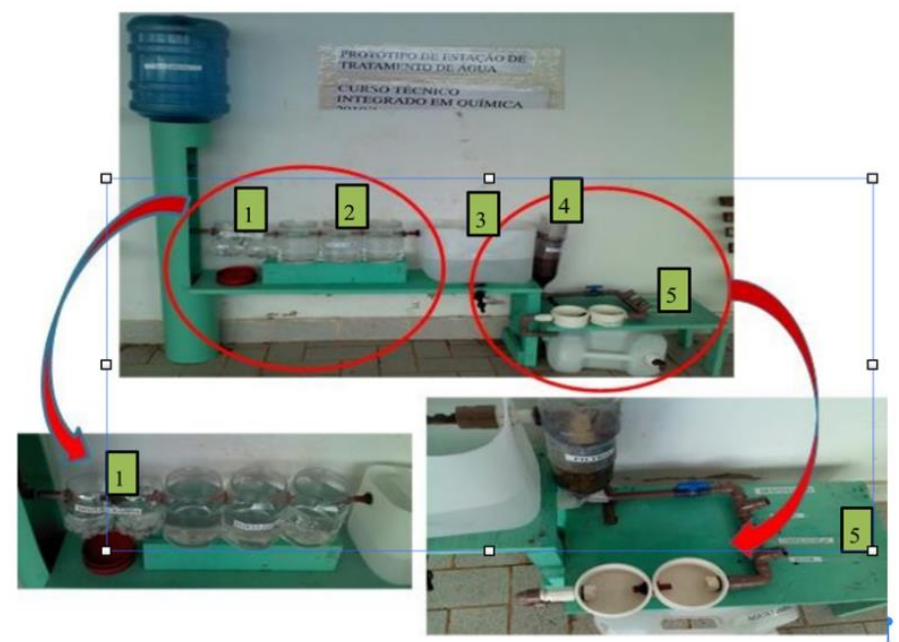

Fonte: Acervo próprio

1. A unidade de mistura rápida, onde ocorre o processo de coagulação, utilizou-se um misturador, o qual permitiu que os alunos empregassem diferentes tipos de coagulantes, sob variadas condições de dosagem e pH;

2. A floculação foi constituída de 3 câmaras operadas em série, com misturadores mecanizados que permitiram a variação da velocidade e do tempo de floculação;

3. A decantação foi constituída por uma câmara apenas, onde a água floculada entrava por meio de uma cortina de distribuição e saia pela canaleta de coleta de água decantada. O protótipo também possuiu descarga de fundo para eliminação do lodo, tal como uma estação convencional;

4. A filtração foi constituída por um único filtro descendente de areia;

5. A desinfecção foi realizada em uma unidade de mistura tipo chicana, onde puderam ser adicionados o cloro o flúor e os agentes de correção de $\mathrm{pH}$.

Quanto à avaliação realizada pelos alunos acerca da metodologia utilizada nas aulas, o item ferramentas de aprendizagem foi a que recebeu maior pontuação, classificada como alta $(4,4)$. Os alunos destacaram, através de conversas informais em sala de aula, que as visitas técnicas e a construção do protótipo foram muito importantes para a aprendizagem do tema abordado. Quanto à participação no processo de ensinoaprendizagem, o mesmo resultou em média alta $(4,2)$. Esse resultado evidencia uma mudança positiva na metodologia, pois o conforme citado por Freitas et al (2009) "antigo modelo pedagógico era centralizado na figura do professor; por consequência, a interferência criativa e crítica dos alunos, e até mesmo dos professores, era limitada". 
Quanto à interação entre os componentes do grupo a média foi alta $(4,0)$ evidenciando que os alunos reconhecem nesse modelo o papel da interação e da troca de experiências entre os colegas como aspecto pedagógico relevante. A compreensão dos temas abordados teve a pontuação considerada satisfatória $(3,8)$. Esse fato pode ser explicado pela falta de familiriade dos alunos com o método, assim alguns tem dificuldades em construir o próprio conhecimento, uma vez o método tradicional está irraigado no imaginário dos alunos, em que o professor apresena o conteúdo pra os alunos. No novo modelo proposto o aluno foi desafiado a buscar as informações necessárias para a resolução de problemas (MESZAROS, 2005; BERBEL, 1998).

Quanto à avaliação do conteúdo, a maior média foi obtida pelo item relação entre os temas abordados com o mundo real, classificada como excelente $(4,5)$ evidenciando assim que o aluno reconhece nesse modelo uma maior aplicabilidade para o conhecimento obtido. Quanto à capacidade de aprofundamento nos temas abordados e a interação do tema com as demais disciplinas a média foi classificada como alta $(4,0)$, o que mostra que os alunos conseguiram desenvolver suas habilidades em diferentes áreas com o uso de um protóytipo, de forma muito mais interativa e interessante do que quando ele estudava separadamente cada disciplina. "Na aprendizagem baseada em problemas há um ensino integrado entre conteúdos e com as diferentes áreas envolvidas, pelo qual os alunos aprendem a aprender e se preparam para resolver problemas relativos à sua futura profissão" (BERBEL, 1998).

Quanto a avaliação do desempenho individual e em grupo, a maior pontuação, classificada como excelente $(4,6)$, foi para o item apresentação do protótipo, o que denota que os alunos tiveram no resultado final sua maior satisfação. A menor pontuação foi para o item desempenho dos demais componentes do grupo nas etapas do projeto, classificada como satisfatória $(3,7)$. Como nesse método cada estudante participa com sua capacidade e criatividade, muitas vezes é difícil para eles reconhecerem o trabalho do colega ou até mesmo as limitações e diferenças na aprendizagem de cada estudante. A sistemática educativa varia de acordo com o indivíduo ou a população alvo (PEREIRA, 2003). "O aprendizado é tão pessoal quanto uma impressão digital, uma vez que diferentes pessoas aprendem de maneiras diferentes. Assim, percebe- se que cada pessoa tem um ritmo de aprendizagem diferente e um grau de atenção diferente" (CHAVES, 2000). A motivação dos estudantes foi classificada como alta $(4,0)$. Esse fator é muito importante nessa metodologia, pois como os estudantes tem maior liberdade na construção do seu conhecimento, mais responsabilidades, mantê-los motivados é um dos papeis 
fundamentais do professor. Assim, segundo Haguenauer, 2005 "é exigido do educador uma mudança do papel de informante para o de construtor de conhecimentos $e$ estimulador da produção dos próprios alunos; não basta o domínio do conhecimento amplo e atualizado; é necessário saber produzir o conhecimento e o que se ensina".

A participação na construção do protótipo também recebeu uma média alta $(4,4)$, evidenciando que os alunos são ativos e participativos quando estão focados. A educação depende da troca entre educadores e educandos e das experiências de cada um, partindo do conhecimento local . Segundo Meszaros, 2005: "É preciso uma nova configuração de conhecimento, que seja marcada pela interdisciplinardade, pela ampliação da liberdade de trajetórias dos estudantes, por currículos e conteúdos mais abertos".

Tabela 1 - Conceito médio atribuído por 30 alunos do curso técnico em Química integrado referente a avaliação do processo e auto-avaliação do estudante no processo de ensino aprendizagem com a utilização da metodologia da problematização

(valoração de 1 a 5)

\begin{tabular}{|l|l|}
\hline Metodologia & 4,2 \\
\hline Participação no processo de ensino-aprendizagem & 4,0 \\
\hline Interação entre os componentes do grupo & 3,8 \\
\hline Compreensão dos temas abordados & 4,4 \\
\hline $\begin{array}{l}\text { Ferramentas de aprendizagem utilizadas (entrevista, video, visitas, seminários, } \\
\text { construção do protótipo) }\end{array}$ & \\
\hline Conteúdo & 4,0 \\
\hline Capacidade de aprofundamento nos temas abordados & 4,5 \\
\hline Relação entre os temas abordados com o mundo real & 4,0 \\
\hline Interação do tema abordado com as diferentes disciplinas do curso & 3,8 \\
\hline Avaliação do desempenho individual ou em grupo & 3,7 \\
\hline Desempenho na realização de todas as etapas do projeto & 4,0 \\
\hline Desempenho dos demais componentes do grupo nas etapas do projeto & 4,4 \\
\hline Motivação para a realização das atividades & 4,6 \\
\hline Participação na construção do protótipo & \\
\hline Apresentação do protótipo & \\
\hline
\end{tabular}

Fonte: Autoras 
A realização dessa avaliação como ferramenta de aprendizagem possibilitou aos estudantes desenvolverem outras habilidades tais como comunicação e discussão. Durante essa atividade, os estudantes relataram pontos positivos e negativos observados durante a construção do conhecimento. Essa ferramenta também possibilitou aos alunos vivenciarem o caráter coletivo da produção das ciências.

Em síntese, através do estudo realizado foi possível perceber um maior envolvimento dos estudantes com o processo de ensino-aprendizagem, sendo responsável pela própria formação, o que possibilitou o desenvolvimento de novas habilidades e uma formação profissional de forma mais integral, humana e resolutiva. Nessa trajetória, surgiram algumas dificuldades que foram superadas ao longo do processo, a aceitação por um modelo novo depende do grupo como um todo, que muitas vezes estão acostumados a modelos prontos, que não requerem discussão ou interpretaçao dos fatos e acabam participando de uma trajetória de formação passiva.

Portanto os desafios estavam além da aplicação da nova metodologia e contrução de novos conhecimentos, era necessário desconstruir aqueles conceitos e hábitos que já estavam enraizados na formação desses estudantes, tais como a criatividade e a autoconfiança (FEUERWERKER, 2000). Vale ressaltar que conforme descreve os autores Freitas et al (2009), todas essas mudanças deverão ser aceitas e vivenciados pelos estudantes e corpo docente, já que a proposta envolve uma mudança na própria concepção de ensino, aprendizado e vida profissional.

\section{Considerações finais}

A aplicação da metodologia ABP na disciplina de tratamento de água, efluentes e esgoto demonstrou potencial para melhoria da compreensão dos conteúdos, aprofundamento das questões trabalhadas, bem como possibilitou o despertar da curiosidade científica, incentivar a criatividade, melhorar as relações sociais entre grupos de trabalho. Assim, os alunos estavam envolvidos um trabalho interdisciplinar do tratamento convencional de água com materiais recicláveis. Além disso, essa metodologia permitiu aos estudantes assimilarem as competências (conhecimentos, habilidades e atitudes) necessárias para a conduta profissional de forma significativa no mundo do trabalho. 
AGRADECIMENTOS: Ao professor Wesley Pimenta de Menezes, docente do IFGCâmpus Goiânia, pelo auxílio na construção do protótipo.

\section{REFERÊNCIAS}

BARAN, E. J. Suplementação de Elementos-Traços. Cadernos Temáticos de Química Nova na Escola - Química Ambiental, n. 6, p. 7-12, 2005.

BARROWS, H. S. "Problem-based Learning in medicine and beyond: a brief overview". In: WILKERSON, L.; GIJSELAERS, W. H. (Ed.). Bringing Problembased Learning to higher education. San Francisco: Jossey- Bass Publishers, p. 3$12,1996$.

BARROWS, H. S.; TAMBLYN, R. M. Problem-based learning: an approach to medical education. New York: Springer,1980.

BERBEL, N. A. N. "Problematization" and Problem-Based Learning: different words or different ways? Interface - Comunicação, Saúde, Educação, v. 2, n. 2, 1998.

BERBEL, N. A. N. A metodologia da problematização com o Arco de Maguerez: uma reflexão teórico-epistemológica. [livro eletrônico]. Londrina, Eduel, 2016. ISBN 978-85-7216-825-0.

BORDENAVE, J. D.; PEREIRA, A. M. Estratégias de ensino-aprendizagem. 19 ed. Petrópolis: Vozes; 1998.

CAMPOS, M. L. A. M.; JARDIM, W. F. Aspectos relevantes da biogeoquímica da Hidrosfera. Cadernos Temáticos de Química Nova na Escola, Química Ambiental, n. 5, p. 18-27, 2003.

CHAVES, E. O. C. Educação orientada para competências e currículo centrado em problemas, 2000. Available at:

<http://www.chaves.com.br/TEXTSELF/PHILOS/comphab. htm>. Acesso em: 10 jul. 2017.

FADINE, P. S.; FADINE, A. A. B. Lixo: desafios e compromissos. Cadernos

Temáticos de Química Nova na Escola, Química Ambiental, Edição especial, n. 1, p. $5-8,2001$.

FREITAS, V. P.; CARVALHO, R. B.; GOMES, M. J.; FIGUEIREDO, M. C.; SILVA, D. D. F. Mudança no processo ensino-aprendizagem nos cursos de graduação em odontologia com utilização de metodologias ativas de ensino e aprendizagem- Learning process modifications in odontology undergraduate courses using actives learning methodologies. RFO, v. 14, n. 2, p. 163-167, 2009.

HAGUENAUER, C. Metodologias e estratégias na educação à distância. Latec.

Adaptado da entrevista concedida à Folha Dirigida, em Janeiro de 2005. Available at: <http:// www.latec.ufrj.br/portfolio/at/4\%20EAD\%20metodologias. pdf > . Acesso em: 10 ago. 2017. 
HOLLENBECK, J. Proceedings of the International Journal of Arts \& Sciences Conference (Germany 2008). Enhanced Student Learning with Problem Based Learning. Disponível em: <http://files.eric.ed.gov/fulltext/ED519989.pdf>. Acesso em: 17 set. 2017.

MUNIZ JUNIOR, J.; RODRIGUES, J. de S.; ASSIS, A.; OLIVEIRA, F. C. de P.; FRANCO, B. C.; MACIEL, F. G. Increasing students' skills in operations management classes: Cumbuca Method as teaching-learning strategy. Gest. Prod., São Carlos, v. 24, n. 4, p. 680-689, 2017. DOI: 10.1590/0104-530x1172-15.

KONDO, M. M.; ROSA, V. A. M. Protótipo de Reator Anaeróbio: Tratamento de Esgoto Doméstico nas Escolas. Química Nova na Escola, Experimentação no Ensino de Química, n. 26, p. 33 - 36, 2007.

LARMER, J.; MERGENDOLLER, J. Why We Changed Our Model of the "8 Essential Elements of PBL”. Buck Institute for Education, 2015. Disponível em: $<$ http://devonshire.ccsd59.org/wp-content/uploads/sites/7/2016/03/8_EssentialElements-of-PBL.pdf>. Acesso em: 10 jan. 2018.

LIRA, M. B.; WULF, M.; AREDES, L. B. S.; RECENA, M. C. P. Protótipo de estação de tratamento de água com materiais de baixo custo: um recurso para o ensino de ciências contextualizado. Revista Ciências \& Ideias, v. 3, n. 2, p.1-9, 2012.

MÉSZÁROS, I. A educação para além do capital. 1. ed. São Paulo: Bontempo; 2005. MORAES, R.; GALIAZZI, M. C. Análise Textual Discursiva, Ed. Unijuí: Ijuí, 2007. PEREIRA, A. C. Odontologia em saúde coletiva. Planejando ações e promovendo saúde. 1. ed. Porto Alegre: Artmed; 2003.

RIBEIRO, C. M. R.; VALVERDE, A. L.; RIBEIRO, M. M. J.; SOUZA, T. S. G.; FAGUNDES, T. S. F.; BITTENCOURT, L. B.; DUTRA, K. D. B.; EPIFÂNIO, R. A. A Videoaula "Cromatografia em Camada Delgada" e a Motivação da Aprendizagem nas Disciplinas Experimentais de Química Orgânica dos Cursos de Química, Engenharia Química e Farmácia da UFF. Rev. Virtual Quim., 2015, v. 7, n. 3, p. 1030-1055.

WALKER, A. E.; LEARY, H.; HMELO-SILVER, C. E.; ERTMER, P. A. Essential Readings in Problem-based Learning. Purdue University Press, 2015 - 384 p.

\section{Como referenciar este artigo}

MACHADO, R. de C. O.; BOHM, G. M. B.; BOHM, E. de M. Problem-based learning: case study in the discipline water treatment, effluent and sewage. Revista on line de Política e Gestão Educacional, Araraquara, v. 13, n. 4, p. 1866-1879, out./dez., 2018. E-ISSN: 1982-5587. DOI: 10.21723/riaee.unesp.v13.n4.out/dez.2018.10497

Submissão em: 09/10/2017

Revisões requeridas: $15 / 12 / 2017$

Aprovação final em: 20/06/2018 